\title{
Implementing Higher Order Thinking Skills in Teaching of Arabic Sociolinguistics
}

\author{
P Zulharby ${ }^{1}$, Y R, Nuruddin ${ }^{2}$ \\ Universitas Negeri Jakarta \\ \{puti.zulharby@unj.ac.id\}
}

\begin{abstract}
Higher Order Thinking Skills should be one of important competencies in modern world. This thinking ability must be owned by students studying in the university level. HOTS is characterized by the ability to think critically, the ability to communicate and resolve problems, as well as the ability to use technology. Thinking skills will be divided into curricula which aim to enable students to solve problems in good education. The lecturers should have a strategy of teaching which is relevant to the need of such higher level of thinking. The literature review that has been carried out in depth mentions that nowadays lecturers are facing some problems on how to prepare and teach such high-level of thinking skills and how to implement the technology in teaching Arabic Sociolinguistic learning. The results of this study, a schema strategy that can be used by the method in teaching Arabic-based sociolinguistics with HOTS abilities.
\end{abstract}

Keywords: HOTS, Sosiolinguistik Arab, Kritis, Kreatif

\section{INTRODUCTION}

Lately there is an idea mentioning that the 21 st century students are also called as millennial generation that is a generation which is born in the rapid development of the digital age. This generation becomes so overwhelmed by many forms of social media communication, cellular technology, technology in the form of rapid search engines and the use of life using technology [1]. Jackson (2011) first connected this idea with the learning process in the classroom [2]. He mentioned that $21^{\text {st }}$ century students are very close and proficient in technology, and it is usual for them to expect the conditions of learning in class to be as easy as using technology as they usually do their everyday life using their technological devices. Eggen and Kauchak (2012) also emphasized that the standard of digital age education is related to the application of technology in learning. Lecturers must be able to prepare their students to live in the digital age, one of which is to use their knowledge in subject matter, learning and technology to facilitate learning experiences, creativity, and innovation in face-to-face situations[3].

Technological advances change the way of thinking. If it is not balanced with the ability of the lecturer to implement technology in the learning process, it can lead to a gap between the conventional learning model commonly used by lecturers and digital learning that is favored by students [4]. If students can find whatever they want to know through a fast search engine, then what is the duty of the lecturer? 
Pana \& Escarlos (2017) mentioned that $21^{\text {st }}$ century learning skills are very closely related to Higer Order Thinking Skill (HOTS), which is a high-level thinking skill that is needed in the digital age [5]. Today's students need to "think" nonstop to be able to respond to real world demands [6]. In an era of open information today, learning is directed towards meaningful learning for life skills, namely having knowledge and having the skills to apply that knowledge in the form of communication. The emphasis of current learning is on observing the development of student thinking processes and learning skills using technology. Thus, the task of the lecturer is to become a facilitator between the process of providing knowledge in the classroom and the use of technological tools as a medium to assist the process of thinking. In addition, the task of the lecturer is to become a mediator to raise student skills in thinking and implement the process of thinking in real life.

In second language teaching, the traditional method separates between cognitive language learning and communicative language learning. Sociolinguistics is the study of how language functions are used in society both individually and in groups. In real life, people use language to talk about what they know and what they want to know more about, not to talk about the language itself. So there needs to be a bridge that connects cognitive learning with communicative in the sociolinguistic domain. The development of communication media today has the effect of providing easy access to provide examples or models for students on how to use the most effective language for communication in a social and academic context that is meaningful and purposeful.

According to Rajendran and Idris (2008), students who are taught how to develop creative thoughts and insights are able to solve more complex problems than those who do not [7]. HOTS is a major component of critical, creative and pedagogical thinking. Creative thinking can help students develop more innovative ideas, ideal perspectives and imaginative insights. HOTS focuses on developing the ability of students to be able to analyze effectively, evaluate by drawing conclusions from existing information and creating (synthesizing) something new. When students are able to utilize the skills of thinking with the help of technology in Sociolinguitic learning activities, and linking to their experience, they have been able to demonstrate high-level thinking skills (HOTS).

\section{RESEARCH METHOD}

This study uses a literature study methodology (literature research methodology). The research was conducted in 3 stages, namely the first stage of gathering information from relevant research sources and scientific developments to find a new knowledge; second stage of identification and exploration of learning needs of high-level thinking skills in the Arabic Sociolinguistic class; the three stages build the link between information and needs by designing HOTS-based learning strategies. The difference between this research and other types of research is that this methodology is not directly related to objects under study, but accesses information from various literature to form a relationship. Yuan mentioned that this research accesses and processes information contained in the literature from various places and perspectives, so the researcher tends to use logical reasons to explore logical relationships between objects [8]. 


\section{RESULT AND DISCUSSION}

Higher order thinking skills (HOTS) were first introduced at the top three levels of Bloom's Taxonomy, namely analysis, synthesis and evaluation. In 2001, Anderson and Krathwohl revised this Taxonomy into analysis, evaluation and creation. Although in reality this taxonomy can serve many learning purposes. But HOTS was built beyond Bloom taxonomy.

HOTS has a very close relationship with the competencies and expertise that must be owned by 21 st century humans. Yen and Halili (2015) mentioned that HOTS produces four dimensions, namely critical thinking, creative thinking, problem solving and decision making [9]. 21 $1^{\text {st }}$ Century Partnership Learning Framework states that learning competencies that must be possessed include: a) critical thinking skills and problem solving skills, the ability to think critically, laterally, and systemically, especially in the context of problem solving. b) The ability to communicate and cooperate (communication and collaboration skills), the ability to communicate and collaborate effectively with various parties. c) The ability to create and renew (creativity and innovation skills), the ability to develop one's creativity to produce innovative breakthroughs. d) information and communications technology literacy, the ability to use information and communication technology to improve performance and daily activities.

HOTS teaching is generally accepted as one of the educational goals. The problem is, there is a fact that nobody knows exactly what the concept means. Many people wonder whether highlevel thinking can really be taught? The ability to think is indeed something that has been given since birth and we do not know the extent of the capacity of thinking abilities. Rajendran (2000) stated that thinking is not obtained automatically, but thinking needs to be trained [7]. Puchta (2012) mentioned the same thing, that thinking is not natural but it is a skill that needs to be developed [10]. If taking into an analogy, students who really think tend to have intelligence and get better grades, than those who don't sharpen their thinking skills as their intelligence will remain the same.

Sociolinguistics teaching in higher education aims at introducing the use of language in society. For students who are learning languages, understanding linguistics and grammar is not enough. It is also important to study it in terms of how the language is used by the community in the student environment. Thus, Sociolinguistics learning is not only an understanding of its theories but how language functions and means in a society.

According to Muklis, Sociolinguistics in language teaching has a role to link language skills (grammatical competence) and the ability to use language in communication (communicative competence) [11]. Language ability is the ability to form language units according to grammar rules, while the ability to use language is the ability to choose and use language units in accordance to the rules and norms inherent in that language.

Hulme revealed that language is communal [12]. That is, language is a sense based on regional ties, loyalty, origin, descent, kinship, and belief in certain inner beliefs. Therefore language is not something that is always right, but needs to be compromised or agreed upon and generally accepted by all parties. Thus, by studying Sociolinguistics, we indirectly learn the culture of the language being studied.

Before implementing HOTS in Arabic Sociolinguistic learning, lecturers should determine what they want to teach to students. This HOTS concept reminds lecturers that there are many things students can learn in the digital era, rather than just memorizing facts and grammar. Ivie (1998) mentioned that HOTS reflects three related criteria: a) Use abstract structures to think since all knowledge has a structure. Therefore, if you want to think abstractly then you must understand the structure of knowledge. b) Organizing information into an integrated system. There is a difference between the thinking of low achieving students and high achieving 
students. Slow students see most of the material presented to him as a series of random, unrelated pieces. Students with extraordinary abilities see things as systems, relationships, and analogies. c) Applying logical thinking and through careful consideration, the habit of thinking logically can be grown in a psychological way, that is, with certain teaching tactics based on an understanding of human behavior [13].

\subsection{Strategies Used by Lecturers}

Here are some strategies that can be used to improve HOTS ( Higher Order Thinking Skills) in Arabic Sociolinguistics learning. They are:

\subsubsection{Teach students to think conceptually}

There are many terms and theories that will be taught in Arabic Sociolinguistics for the elementary level for example the term or theory of code switching, code mixing, types of variation and variety of languages, diglosia. Conceptual thinking can be done by dismantling theoretical formations and rearranging them in other forms, for example by grouping the theory into their minds, determining which are abstract and concrete, or which are verbal and nonverbal. Thinking strategies like this can hone students critical thinking skills such as analyzing and synthesizing theories, not memorizing theories. Students are involved in finding and finding examples of these theories in their daily lives interacting using language.

\subsubsection{Teach students to make conclusions}

In addition to conceptual thinking, in developing logical thinking skills, students need to be trained to make logical conclusions. Lecturers can present evidence or facts, then play a role in guiding the student's process of connecting concepts with evidence or facts one of the examples is concluding temporal dialect concept. Temporal dialects are variations of language that develop in certain periods. Lecturers can present communication video footage from time to time. From this thinking activity, students are directed to connect the concepts that have existed in their minds with what happened in the example of communication that was aired through video. In this way, a deeper network of knowledge and clarity will be created.

\subsubsection{Teach students productive and creative thinking}

Moseley, Elliot, Gregson and Higgins (2005) mention three frameworks of cognition, namely gathering information, building understanding and producing productive thinking [14]. Someone who can produce a productive mind must go through a phase of gathering information and building understanding. But not everyone is able to reach this third phase as most students stop in the first phase, which is only gathering information. Thinking skills will not be honed if the information received only in the form of raw/abstract without being processed by the brain becomes an understanding. Students who are honed through three phases can create creative ideas or views.

\subsubsection{Perform Effective Questions and Answers}

Thomas and Thorne (2009) identified two main categories of question and answer relationships (1) questions where answers can be obtained from facts documented in the text (book questions) and (2) questions that require own experience (head questions) [15]. This 
allows students to be aware of the relationship between textual information and prior knowledge that helps them determining what strategies will be used when looking for answers to questions. Keengwe (2014) stated that active constructivist learning is characterized by students who ask questions and this is highly valued and students are seen as thinkers and especially when they work in groups [16]. Students learn more when they are responsible for their own learning. Constructivist theories view learning not as sequential and linear, but it is seen in such integrated and complex way. Learning is a process that involves students in sensemaking activities shaped by prior knowledge. The activity is structured so that students make and control the development of their own learning from beginning to end

\subsubsection{Brainstorming with group learning}

The relationship between cooperative learning and high order thinking skill cannot be separated. Kang (1999) noted that students in the class with the lecture method often become passive because information is only transmitted, while thinkers learn by asking questions, reflecting ideas and exchanging ideas with others [17]. This means that a cooperative learning environment provides opportunities for students to engage in high-level thinking skills and to develop upper-level linguistic and cognitive abilities.

One of the strategies that can be applied for example is dividing students into several groups. In this group, they are allowed to exchange ideas and reflect solutions to certain problems. When a student produces ideas, other students are also challenged to think and develop better ideas similarly so that they are involved in higher thinking [18]. The purpose of doing this is that students are accustomed to being faced with three levels of higher level of thinking, namely analysis, evaluation and creation.

\subsubsection{Make situations and design problems}

Lecturers teaching Arabic sociolinguistics are frequently faced with problems regarding language and culture. Responding to this challenge, lecturers can create a situation and design a form of language permissions to build student involvement in finding solutions to the problem, building initiatives by students or groups of students. In addition, lecturers can apply projectbased learning. Project-based learning (PBL) is one of the most effective ways to engage students with their learning content. PBL gives students the opportunity to solve real world problems.

\section{CONCLUSIONS}

This study reviews the concepts and practices of learning using HOTS. Many other studies have explained the importance of HOTS in the teaching and learning process, but there is no literature discusses strategies or ways in which lecturers can use HOTS to teach Arabic Sociolinguistics in Arabic or other language classrooms that also study Sociolinguistics. Therefore the results of this study will add to the literature on HOTS implementation and some strategies that can be adopted by lecturers in teaching.

The following recommendations provide information for lecturers in designing Arabic Sociolinguistics learning by promoting HOTS (high Oreder Thinking Skills). They are: (a)Training students to be involved in the evaluation process because critically they will be involved in the analysis, evaluation and creating an argument and idea about the assessment; (b) Using instructional learning strategies such as problem-based learning so students are actively involved in solving problems with high-level thinking; (c) Involving students in brainstorming 
to get ideas and solutions that are suitable for their generation; (d) Getting students used to using cooperative learning to build linkages between students.

\section{REFERENCES}

[1] L. Edwards, "Education, Technology and Higher Order Thinking Skills," in Paper presented at the AARE Conference 2016, 2016.

[2] M. J. Jackson, M. M. Helms, W. T. Jackson, and J. R. Gum, "Student Expectations of Technology-Enhanced Pedagogy: A Ten-Year Comparison,” J. Educ. Bus., vol. 86, no. 5, pp. 294-301, 2011.

[3] P. Eggen and D. Kauchak, Strategi dan Model Pembelajaran, Mengajarkan Konten dan Keterampilan Berfikir, 6th ed. Jakarta: Indeks, 2012.

[4] L. Gettler, "Big Googler is doing the thinking for you," in Feature Article, Sydney Morning Herald, 2010.

[5] G. U. Pana and G. S. Escarlos, "Contemporary Teaching Strategies on Students Attitude Academic Performance And Acquisition Of The 21st Century Skills," Int. J. Sci. Technol. Res., vol. 6, no. 08, 2017.

[6] P. Vijayaratnam, "Developing higher order thinking skills and team commitment via group problem solving: A bridge to the real world," in 8th International Language for Specific Purposes (LSP) Seminar: Aligning Theoretical Knowledge with Professional Practice, 2012.

[7] N. Rajendran, "Language teaching and the enhancement of higher-order thinking skills," in Southeast Asian Ministers of Education Organization Regional Language Centre's 35th International Seminar, 2000.

[8] C.-N. Hsieh and Y. Wang, "Speaking proficiency of young language students: A discourse-analytic study," Lang. Test., 2017.

[9] T. S. Yen and S. H. Halili, "Effective Teaching of Higher-Order Thinking (Hot) in Education," Online J. Distance Educ. e-Learning, vol. 3, no. 2, pp. 41-47, 2015.

[10] H. Puchta, "Developing thinking skills in the young learners' classroom," 2012. .

[11] M. Muklis, "Pengajaran Bahasa dalam Perspektif Sosiolinguistik," J. Din. Ilmu, 2011.

[12] R. Wardhaugh and J. M. Fuller, An Introduction to Sociolinguistics, 7th ed. Oxford: John Wiley \& Sons, 2015.

[13] S. D. Ivie, “Ausubel's Learning Theory: An Approach to Teaching Higher Order Thinking Skills," High Sch. J., vol. 82, no. 1, pp. 35-42, 2016.

[14] D. Moseley et al., "Frameworks for Thinking," Cambridge: Cambridge University Press, 2005.

[15] Thomas and G. Thorne, "How to increase Higher Order Thinking Centre for Development and Learning," 2009.

[16] J. Keengwe, G. Onchwari, and J. Oigara, Promoting Active Learning through the Flipped Classroom Model. Hershey: Information Science Reference, 2014.

[17] S. Kang, "Higher Order Thinking Skills in Language Education. The Korean Language in America," J. Storage, vol. 3, 1999.

[18] K. Saddhono and M. Rohmadi, "A Sociolinguistics Study on the Use of the Javanese Language in the Learning Process in Primary Schools in Surakarta, Central Java, Indonesia." Int. Edu. Stu., vol. 7 no.6 pp 25-30, 2014 